\title{
Broca's Area and Language Disorders in the Child
}

\author{
RAMONA MIHAELA NEDELCUTA ${ }^{*}$, GIGI CALIN2*, VLAD DUMITRU BALEANU ${ }^{*}$, DRAGOS VIRGIL DAVITOIU ${ }^{3}$, \\ DANIEL IULIAN VOICULESCU ${ }^{4}$, CECIL SORIN MIREA ${ }^{5}$, TIBERIU STEFANITA TENEA COJ AN ${ }^{6}$, BOGDAN SOCEA $^{7}$, \\ DRAGOS OVIDIU ALEXANDRU ${ }^{*}$, COSMIN ALEXANDRU CIORA ${ }^{9}$, MIHAI RELU STANESCU ${ }^{10}$, RADU STANESCU ${ }^{10}$ \\ 'University of Medicine and Pharmacy of Craiova, Pediatrics Department, 2 Petru Rares Str., 200349, Craiova, Romania \\ 2University of Medicine and Pharmacy of Craiova, Surgery Department, Clinical Emergency Hospital Sf. Pantelimon, \\ 340-342 Pantelimon Road, 021659, Bucharest, Romania \\ ${ }^{3} U$ niversity of Medicine and Pharmacy of Bucharest, Surgery Department, Clinical Emergency Hospital Sf. Pantelimon Bucharest, \\ 340-342 Pantelimon Road, 021659, Bucharest, Romania \\ ${ }^{4}$ University of Medicine and Pharmacy Carol Davila Bucharest, Department of Surgery Universitary Emergency Hospital Bucharest, \\ 169 Splaiul Indepenei, 050098, Bucharest, Romania \\ 5 University of Medicine and Pharmacy of Craiova, Surgery Department, 2 Petru Rares Str., 200349, Craiova, Romania \\ EUniversity of Medicine and Pharmacy of Craiova, Department of Surgery, CFR Hospital of Craiova, Stirbei-Voda Str., 200374,Craiova, \\ Romania \\ ${ }^{7}$ General Surgery Clinic, Emergency Clinical Hospital Sfantul Pantelimon, 340-342 Pantelimon Road, 021659, Bucharest, Romania \\ 8University of Medicine and Pharmacy of Craiova, Department of Medical Informatics and Biostatistics, 661 Mai Blvd, 200638, \\ Craiova Romania \\ ${ }^{9}$ Carol Davila University of Medicine and Pharmacy, Discipline of Gastroenterology and Hepatology, 8 Eroii Revolutiei Blvd., \\ 050474, Bucharest, Romania \\ ${ }^{10}$ University of Medicine and Pharmacy of Craiova, Department of Morphological Sciences, Petru Rares Str., 200349, Craiova, \\ Romania
}

\begin{abstract}
Language, the second signaling system, complexly integrates the body into the environment, assures interference with fellows, and modulates the thoughts and feelings to be communicated to others. The embryonic development of the encephalus is performed early on days 16-20 and determines the appearance of the neuroenteric canal and the appearance of the tridermic embryonic disc. The sketch of the Broca area has been researched from anatomopathological point of view, following a study carried out on fetal brain samples taken postpartum, shows that the sketches of the future Broca area are observed in gestation at week 23. Neural migration and glial cell distribution reveal the existence of a detectable neuroblasts reservoir, beginning at week 18, with exuberant evolution to a organized histoarchitectonics at 20-23 week. The premises of a future impairment in the development of the Broca area and, implicitly, of language can be established early in fetal life.
\end{abstract}

Keywords: Broca area, language, neural migration, cerebral histoarchitectonics

Cortical location of the language centers - the level of the 8 area on the frontal lobe side: the motor center of the language, Brodman's areas 44-45 of the inferior frontal gyrus - the center of speech Broca - the center of the inferior frontal gyrus that coordinates muscle contraction and pronunciation of the words $[1,2]$.

Embryogenically, in the 25th day the anterior neurophoid is closed, the rostral extremity of the neural tube presents 3 dilations, prosencephlon, mesencephalon and the rhombencephalon. In the 5 th week from prosencephlon is formed telencephalon - cerebral hemispheres, from the encephalus, the thalamus, the hypothalamus [3].

The prosencephlon divide into telencephalon and diencephalon. Telencephalus is the premise of brain hemispheres, the dorsal part forms bark, and the ventral forms the basal nuclei. At this level, the telencephalon, the channel of the neural tube forms the lateral ventricles.

Last studies suggest that the Broca's area presents two divisions: one is used in the language process and the other participates to the general cognitive functions and it has an ample structure of a fronto-parietal shared network. Both subdivisions communicate each other.

The language, the second signal system, allows the communication of the thoughts, the adjustment and the modulating of the lived experiences through the association different various symbols $[4,5]$.
The complex neuronal substrate was represented by a localized system in the perisylvian region of the left hemisphere, the anterior zone is called area Broca and is located in the posterior part of the inferior frontal gyrus and the zones that surround the heteromedial prefrontal cortex. Its function is to translate the neural representations in articulated sequences which stay on the basis of spoken language and also to order the translations of the neural impulses in order to have a syntax corresponding to the meaning.

The posterior zone is located in $1 / 3$ posteriorly of the superior temporal gyrus, and the zone that surround the inferior parietal lobe transforms the sensorial stimulus in order to permit an associations that lead to understanding the meaning [6-8].

The delay in language development had during the time controversies concerning the precocity of the diagnosis moment and the promptness of the therapeutic surgery. In our country, it was followed a literary model - Lucian Blaga - declared himself until 4 years old speechless like a swan [9-12].

However, the studies conducted show that the discovery of evident language acquisition delays can be achieved at 2 years old and the therapy must follow immediately after diagnosis. 
Incriminated factors are multiple: cerebral and cognitive dysfunctions, neurodevelopmental disorders, intellectual disabilities, hearing disabilities, prematurity, autistic spectrum disorders, cerebral palsy, brain injury, neurological disorders, mechanical structure impairments, verbal aphasia, elective mutism, emotional troubles, neurosis etc[13-18].

A study conducted over 3 years (between 2-5 years) on 2184 pediatric patients showed a 9.25 (\%) 202 patients with retard in the language development [19-22].

A histologenetics study was realized and also an embryogenetic progressive perspective to be able to illustrate the germ of the neurodevelopment disorders.

\section{Experimental part}

Methods and materials

To study the cortical histology of the Broca area, we have taken fragments from the superior versant of the lateral hemisphere of the left brain hemisphere from fetuses with gestational age between 16 and 23 weeks, recorded with perinatal death in Municipal Clinical Hospital Filantropia from Craiova. The fragments taken were subjected to the classical histological processing: fixation in 10\% formalin, dehydration, paraffin inclusion, microtome sectioning, 5 microns thickness, deparaffinization and staining with hematoxylin and eosin. The preparations obtained were examined with the research microscope Nikon E600; Microphotographs taken with Nikon DN100 camera were purchased and processed using the LuciaNet system.

In days 16-20 after fecundation are the period of neuroenteric channel appearance and the separation of the three endo, exo and mesoblast layers which create the tridermic embryonic disc, and implicitly the premise of NS development (derived from the embryonic ectoderm).

In the 2 nd month the embryo receives humanoid forms with the voluminous cephalic extremity with cerebral vesicles, the primordial of the hemispheres situated anterior.

The second month ( 8 weeks) of pregnancy is labile and sensitive to the toxic factors; due to the rapidity and amplitude in which the processes of differentiation are carried out, any disturbance of the induction mechanism leads to mutagenic effects

At 12 weeks of gestation, the brain is fully formed. It was done the sampling from the left superior versant of the sulcus and of the cerebral hemispheres for fetuses of 16-23.

In the 4th month (16 weeks) there is anatomopathologically an outline of the cerebral ditc, with an uncertainty delimitation between the frontal and parietal lobes, the neuroblasts and the glial cells make an homogeneous, undifferentiated layer.

At 18 weeks begins to visualize the part of the glial sector that delimits the cortical neuronal migration

At 23 weeks, the side sulcus is visible and implicitly the location of the future area Broca

At the 16-week-old fetus, the lateral sulcus is present, but the central ditch is sketched only very vaguely to the superior edge of the cerebral hemisphere. For this reason, a delimitation between the frontal lobe and the parietal lobe could not be made. As a result, was collected the entire superior part of lateral sulcus. To the microscopic examination, there are no qualitative and quantitative differences in the cortex development on all length of the collected sample.

\section{Results and discussions}

The paraventricular area is a cellular rich populated making a thick and relatively homogeneous layer of neuroblasts and glial cells. When examining with a stronger objective, a higher density of neuroblasts under the germinal layer and is observed. Deeply, the densely populated cellular layer sends extensions to the cerebral cortex (fig. 1) through the marginal area (the future white matter). Even if the cellular density is lower than in the paraventricular zone, the cells from these columns are similar qualitative with those from the origin area (fig. 2). The cerebral cortex has a homogeneous structure in a parallel sense and also perpendicular on its surface, however there is a cellular hiatus between the thin subpial area and the thick and dense depth layer.

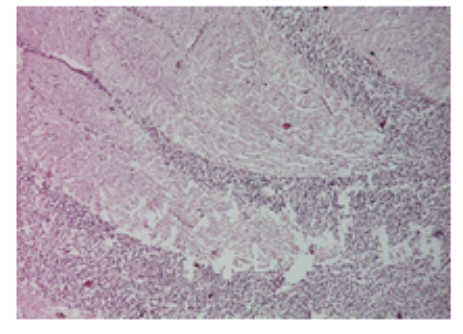

Fig. 1. Extensions to the cerebral cortex

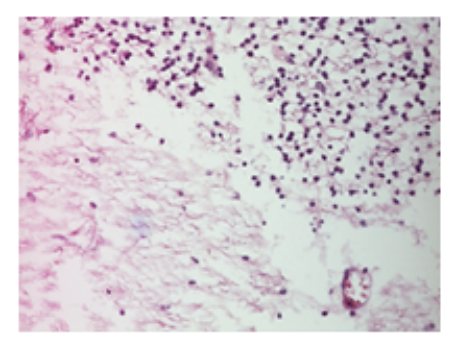

Fig. 2. Origin area

The same mechanism of development can be observed in the 18-week-old fetus brain: a rich populated paraventricular reservoir with neuroblasts (fig. 3), from which start thin rays of radial migration (fig. 4) start to the cortex already undifferentiated stratigraphic, in which, with a stronger objective, one can observe the glial tracers that marks cortical neuronal migration, perpendicular on the pial surface.

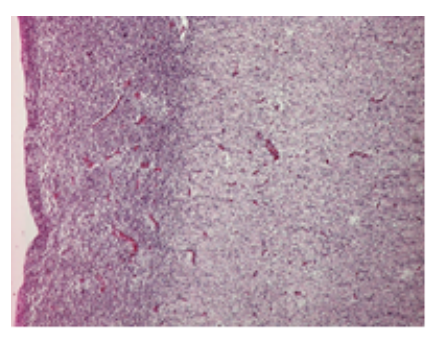

Fig. 3. Neuroblasts

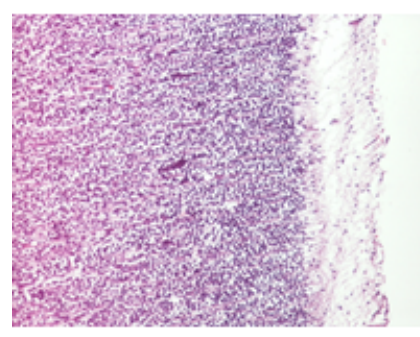

Fig. 4. Thin rays of radial migration

The paraventricular migration bands are evident in our 21-week-old fetus (fig. 5 and fig. 6), despite the cortical autolysis process generated by the intrauterine fetus death. Even in this case we can not see a cortical stratigraphy.

Instead of it, to the 23-week-old fetus we noticed an obvious sketch of the lateral sulcus, which allowed a more accurate localization of the area in which will be formed the Broca's area.The paraventricular zone was well 


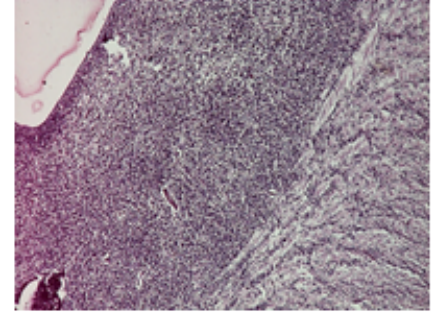

Fig. 5. Paraventricular migration

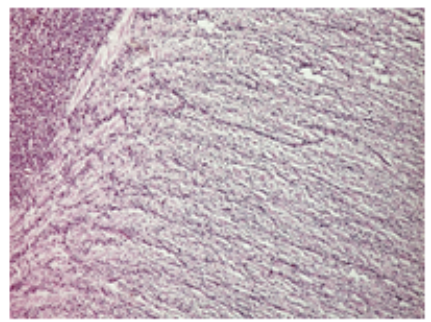

Fig. 6. Paraventricular migration

highlighted, but cellular depletion phenomena distributed as diffuse islets located inside it, as well as with a lacunar zone relatively large that separates the paraventricular zone from the marginal zone, paradoxically, richer cellular .

Even if this lacunar zone was crossed by neuroblastic bands glial guided which were starting under bundles with perivascular origin (fig. 7). In the marginal zone, the neuroblasts regrouped in a rich cellular layer were directed to the cortical area under a column form almost parallel but diffusely delimitated (fig. 8). The cortex presents a histoarhitectonic stratification better outlined, easily distinguishing 3 or even 4 layers. The deepest, richest cellular zone presented perpendicular bands to the pial surface, guiding the migration and differentiation of the future pyramidal layers.

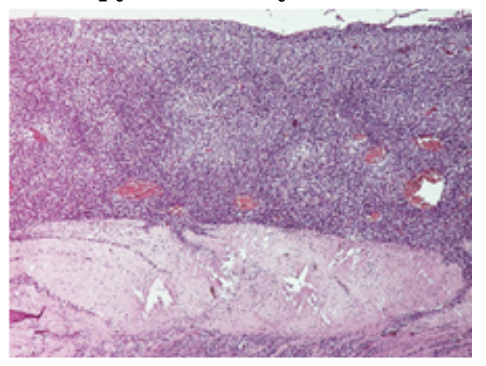

Fig. 7. Perivascular origin

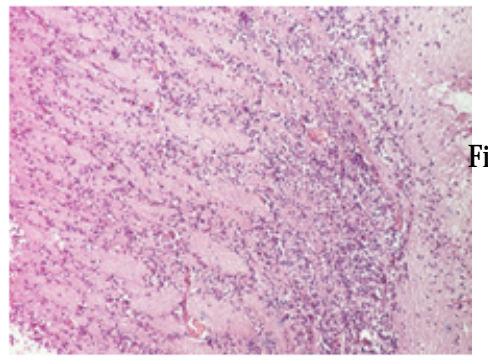

Fig. 8. Neuroblasts regrouped in a rich cellular layer

\section{Conclusions}

The epigenetic factors have an involvement with an identical amount at least equal to genetic factors. The treatment of language deficiency can begin from the preconception phase and throughoutthe pregnancy period, to prevent neurodevelopment disorders.

\section{References}

1.NEDELCUTA, R.M., BALEANU, V.D., CIORA, C., CALIN, G., STANESCU, M.R., DAVITOIU, D.V., TENEA COJAN, T.S., SOCEA, B., VOICULESCU D.I., ALEXANDRU, D.O., STANESCU, R., Possible Retard in the Language Development to the Children Born through IVF (In Vitro Fertilisation), Rev. Chim. (Bucharest), 70, no. 5, 2019, p.1859-1862.
2.AMUNTS K, SCHLEICHER A, BÜRGEL U, MOHLBERG H, UYLINGS HB, ZILLES K. Broca's region revisited: cytoarchitecture and intersubject variability. J Comp Neurol 412, p.319-341, 1999.

3.BAHLMANN J, SCHUBOTZ R, FRIEDERICI AD. Hierarchical artificial grammar processing engages Broca's area. Neuroimage 42. p.525$534,2008$.

4.BEHRENS TEJ , et al. Non-invasive mapping of connections between human thalamus and cortex using diffusing imaging. Nat Neurosci 6 , p.750-757, 2003

5.COOKE A, et al. Neural basis for sentence comprehension: Grammatical and short-term memory components. Hum Brain Mapp 15, p.80-94, 2002.

6.FEDORENKO E, GIBSON E, ROHDE D. The nature of working memory capacity in sentence comprehension: Evidence against domain specific resources. J Mem Lang 54, p.541-553, 2006.

7.FRIEDERICI AD, ALTER K. Lateralization of auditory language functions: A dynamic dual pathway model. Brain Lang 89, p.267-276, 2004.

8.FRIEDERICI AD, BAHLMANN J, HEIM S, SCHUBOTZ RI, ANWANDER $A$. The brain differentiates human and non-human grammars: Functional localization and structural connectivity. Proc Natl Acad Sci USA 103, p.2458-2463, 2006a.

9.FRIEDERICI AD, FIEBACH CJ, SCHLESEWSKY M, BORNKESSEL ID, VON CRAMON DY. Processing linguistic complexity and grammaticality in the left frontal cortex. Cereb Cortex 16, p.1709-1717, 2006b.

10.GRODZINSKY Y, FRIEDERICI AD. Neuroimaging of syntax and syntactic processing. Curr Opin Neurobiol 16, p.240-246, 2006.

11.GRODZINSKY Y, SANTI A. The battle for Broca's region. Trends Cogn Sci 12, p.474-480, 2008.

12.GRODZINSKY Y. The neurology of syntax: Language use without Broca's area. Behav Brain Sci 23, p.1-71, 2000.

13.HAGOORT P. The fractionation of spoken language understanding by measuring electrical and magnetic brain signals. Philos Trans $\mathrm{R}$ Soc Lond B Biol Sci 363, p.1055-1069, 2008.

14.HICKOK G, POEPPEL D. Dorsal and ventral streams: A framework for understanding aspects of the functional anatomy of language. Cognition 92, p.67-99, 2004.

15.VLADU, I.M., RADU, L., GIRGAVU, S.R., TENEA COJAN, T.S., ENE, C.G., CALBOREAN, V., GHEORMAN, V., CLENCIU, D. Alteration of Glucidic Metabolism in Relation with Visceral Adiposity Index. Rev.Chim. (Bucharest), 69, no.9, 2018, p. 2479-2481.

16.CORICI O.M., TANASIE C.A., ALEXANDRU D.O., FLORESCU M.C., COMANESCU M.V., KAMAL K.C., TENEA-COJAN T.S., IANCAU M, DINESCU S.N. A morpho-functional study using PEP/LVET ratio and global longitudinal strain in patients with dilated cardiomyopathy. ROM J MORPHOL EMBRYOL. 2018, 59(1), p.93-103.

17.HICKOK G, POEPPEL D. The cortical organization of speech perception. Nat Rev Neurosci 8, p.393-402, 2007.

18.LOHMANN G, HOEHL S, BRAUER J, DANIELMEIER C, BORNKESSELSCHLESEWSKY I, BAHLMANN J , TURNER R, FRIEDERICI AD. Setting the frame: The human brain activates a basic low-frequency network for language processing. Cereb Cortex 20, p.1286-1292, 2010.

19.MUSSO M, MORO A, GLAUCHE V, RIJ NTJES M, REICHENBACH J, BUCHEL C, WEILLER C. Broca's area and the language instinct. Nat Neurosci 6, p.774-781, 2003.

20.OBLESER J, MEYER L, FRIEDERICI AD. Dynamic assignment of neural resources in auditory comprehension of complex sentences. Neuroimage 56, p.2310-2320, 2011.

21.DUYGU OZGE, AYLIN KÜNTAY AND JESSE SNEDEKER, Why wait for the verb? Turkish speaking children use case markers for incremental language comprehension, Cognition, 10.1016/j.cognition.2018.10.026, 183, p.152-180, (2019).

22.LYNDA KENNEDY, JACOPO ROMOLI, LYN TIEU, VINCENZO MOSCATI AND RAFFAELLA FOLLI, Beyond the scope of acquisition: A novel perspective on the isomorphism effect from Broca's aphasia, Language Acquisition, 10.1080/10489223.2018.1502772, 26 (2), p. 144-152, 2018.

Manuscript received: 19.02 .2019 